\title{
Testing Becker's Efficient Marriage Market Hypothesis And Its Implications For Spouse Selection And Marital Transfers In India
}

Sonia Dalmia (E-mail: dalmias@gvsu.edu), Grand Valley State University

\begin{abstract}
This paper constructs an empirical model of spouse selection based on Becker's efficient marriage market hypothesis to examine how equilibrium sorting takes place in marriage markets in India. It finds that education of the groom and age of the bride has the largest effect on matching behavior in India. More importantly, it finds that marital transfers from brides and their families to grooms and their families increase the likelihood of women marrying men of similar type.
\end{abstract}

\section{Introduction}

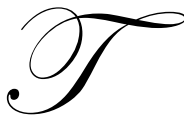

his paper examines how equilibrium sorting takes place in marriage markets in India. It constructs an empirical model of spouse selection based on Becker's (1973) efficient marriage market hypothesis, in which stable assignments of marriage partners are derived from a utility maximization problem. Utility, in this model, depends on consumption of commodities produced jointly by the husband and wife according to a household production function. Marriage assignments are stable if no matched individual would rather be single and if no unmatched pair prefers each other to their assigned partners. Marriage markets are efficient if men and women are matched in such a way that maximizes total household commodity output over all marriages. By specifying a marital production function and introducing the influence of individual characteristics in the matching technology, this paper creates a matching algorithm and uses the estimated parameters to examine positive assortative mating with respect to nonmarket characteristics.

The theoretical literature on who marries whom treats marriage as a voluntary arrangement between men and women (see Bergstrom 1997, Mortenson 1988 and Weiss 1977 for surveys of the literature on marriage, matching and economics of the family). It is natural, then, for economists to analyze the assignment of partners within a market framework (Becker 1991; Gale and Shapley 1962). In Becker's model, marriage occurs only if the gains from marriage are positive and partners believe that the utility of being married is higher than the utility of remaining single. A marriage market forms from competition among single men and women seeking mates. Marital matches are responsive to the personal traits of individuals, which influence their market and nonmarket productivity and are inputs to the household production function. The marriage market functions by choosing the optimal sorting of men and women that maximizes the average gain over all marriages. This maximization process yields two possible outcomes: positive assortative mating--likes pair with likes--with respect to complementary traits (age, race, education) and negative assortative mating--opposites match-- with respect to substitute traits (wages and hours worked).

A large literature exists on patterns of marital matching on a wide variety of attributes, with most research produced by sociologists and psychologists. While, Becker's prediction of negative assortative mating on spouse's wages and hours worked has received little empirical support (Zhang and Lui 2003; Nakostein and Zimmer 2001; Lam 1988), positive assortative mating has been more commonly observed, as indicated by the conventional measure of simple correlations, in the literature. Positive correlations are reported for intelligence, age, education, race, nonmarket income, religion, ethnic origin, and height of spouses (Mare 1991; Epstein and Guttman 1984). While others have studied patterns of marital sorting, this paper makes several contributions to the literature. First, with the exception of Suen and Lui (1999) and Jepsen and Jepsen (2002) empirical studies on marital assignments have fo- 
cused on a single trait only. The matching process is a function of multiple characteristics that individuals bring to the marriage; such a simplification would, therefore, not be practical. To address this issue, a vector of traits is used to capture a potential mate's attractiveness in the marriage market. The multivariate technique is then utilized to not only assess patterns of assortative mating with respect to any particular trait, but also to isolate factors that are important in selecting mates in India.

Second, despite the repeated usage of Becker's theory of marriage the literature on marriage and matching has completely ignored his hypothesis that marriage markets maximize aggregate marital output, i.e., marriage markets are efficient. In contrast, like Suen and Lui (1999) this paper utilizes Becker's framework of marital sorting to find the optimal male-female pairing that maximizes the sum of marital output. Finally, for any given demographically defined aggregate of individuals, assortative matching requires access to a sufficient pool of members of opposite sex with similarly defined characteristics. However, the regulatory systems of Indian society enforce a variety of norms and sometimes specific rules about who may marry whom. For example, marriages are arranged by the parents of the prospective spouses, are subject to certain rules of caste, kinship, religion and geographic region and require the bride's parents to provide a dowry to the groom and his household (Banerjee 1999). As a result, these social constraints may impose barriers on mate selection and negatively influence the availability of partners, thus indirectly affecting the degree of assortative mating. To address this issue, the paper constructs a "marriage index" for each male and female in the sample on the basis of his or her observed traits. The marriage index which is a measure of an individual's desirability as a mate is then utilized to form a match matrix to examine the extent of assortative mating in India.

Results support Becker's predictions of positive assortative mating with respect to age and schooling. In examining matching patterns to isolate the factors that affect marital choice results indicate that while years of schooling of the groom has the largest effect on matching behavior, it is the age of the bride that affects mate selection and the organization of marriage markets in India. Furthermore, equilibrium sorting indicates that thirty-four percent of the marriages in India occur between men and women of similar type. Most importantly, results show that dowry increases the likelihood of women marrying men of similar type. This is an important result, as it lends support to the equalizing differences role of marital arrangements in India (Dalmia 2003).

\section{Estimation Methodology}

Consider two types of agents to be matched, males $(M)$ and females $(F)$. Let $N$ denote the number of women in the marriage market (which also equals the number of men). Individuals are heterogeneous with respect to their observed and unobserved traits such as age, education, and income. It is assumed that these attributes, which indicate an individual's type, can be collectively represented by one-dimensional indices $M_{i}$ for male $i$ and $F_{j}$ for female $j$. These indices measure the marriageability of an individual in terms of qualities that make him or her a desirable spouse in the marriage market. Consequently, it is assumed that a higher type individual is always preferred and that each agent tries to find a partner who maximizes his or her well being, with well being measured by the consumption of household produced commodities $(Z)$ such as, love, companionship, quality and quantity of children. The match quality is measured by the household production, with the couple's types as inputs to match production. To allow for both increasing returns to scale and complementarity between the couples type, the match production is assumed to be the product of couple's type:

$$
Z_{i j}=M_{i} F_{j}+\varepsilon_{i j}
$$

Single observed characteristics such as height, wage and education etc. do not offer a perfect measure on marriageability of an individual in the marriage market. Other characteristics of marriage partners such as beauty, personality, and temperament are also important to the choice of a mate. However, not all of the characteristics of participants in the marriage market may be observable by the researcher hence, the measurement error term, $\varepsilon_{i j}$ in equation (1). 
Let males $M_{i}$ and females $F_{j}$ be characterized by their age (A) and years of schooling (S). That is:

$$
\begin{aligned}
& M_{i}=e^{\alpha A_{i}^{m}+(1-\alpha) S_{i}^{m}} \\
& F_{j}=e^{\beta A_{j}^{f}+(1-\beta) S_{j}^{f}}
\end{aligned}
$$

where superscripts $m$ and $f$ refer to male and female. Using equations (1) and (2), the match quality can be written as

$$
Z_{i j}=e^{\alpha A_{i}^{m}+(1-\alpha) S_{i}^{m}+\beta A_{j}^{f}+(1-\beta) S_{j}^{f}}+\varepsilon_{i j}
$$

Women have traditionally brought wealth to their marriage in the form of a dowry in India (Goody 1973). Whatever other functions the dowry serves, it could enhance the marriageability of a female in the marriage market as well as proxy for her unobserved traits such as beauty. Thus, to examine the role of dowry in sorting individuals in the marriage market, the amount of dowry (D) transferred by the bride household to the groom household is included along with the bride's age and years of schooling to construct her marriageability index, viz:

$$
F_{j}=e^{\beta_{1} A_{j}^{f}+\beta_{2} S_{j}^{f}+\left(1-\beta_{1}-\beta_{2}\right) D_{j}^{f}}
$$

The following payoff matrix can represent the household commodity output produced by all possible monogamous matches:

\begin{tabular}{l|lllll} 
& $F_{1}$ & $F_{2}$ & $\cdot$ & $\cdot$ & $F_{N}$ \\
\hline$M_{1}$ & $Z_{11}$ & $Z_{12}$ & $\cdot$ & $\cdot$ & $Z_{1 N}$ \\
$M_{2}$ & $Z_{21}$ & $Z_{22}$ & $\cdot$ & $\cdot$ & $Z_{2 N}$ \\
$\cdot$ & $\cdot$ & $\cdot$ & $\cdot$ & $\cdot$ & $\cdot$ \\
$\cdot$ & $\cdot$ & $\cdot$ & $\cdot$ & $\cdot$ & $\cdot$ \\
$M_{N}$ & $Z_{N 1}$ & $Z_{N 2}$ & $\cdot$ & $\cdot$ & $Z_{N N}$
\end{tabular}

where $M_{1}, M_{2}, \ldots, M_{N}$ and $F_{1}, F_{2}, \ldots, F_{N}$ refer to males and females of different qualities. With the quality measures of males and females given, the optimal assignment can be derived from maximizing the marital output over all marriages:

$Z^{*}=\operatorname{Max} \sum_{i, j} \delta_{i j} Z_{i j}$

where $\delta_{i j}$ is the permutation matrix representing the number of matches of each type. If males and females are ranked in the same order, the higher their type the better, that is $M_{1}<M_{2}<\ldots<M_{N}$ and $F_{1}<F_{2}<\ldots .<F_{N}$, the only optimal solution to the maximization problem is to match males and females along the main "core" diagonal. In other words, $\delta_{i j}$, must be a diagonal matrix. 
In the multivariate case, the parameters of the model $\alpha$ and $\beta$ are also of interest as they not only reveal which traits have the largest effect on match formation but also indicate whether there is positive or negative assortative mating with respect to the characteristics used in measuring each individual's attractiveness in the marriage market. In particular, if $\alpha \beta>0$, positive assortative mating is optimal and the trait is categorized as a complement and if $\alpha \beta<0$, negative assortative mating is optimal and the trait is categorized as a substitute. For instance, if potential spouses differ in their age, positive assortative mating will characterize optimal sorting of partners if:

$$
\frac{\partial Z_{i j}\left(A_{i}^{m}, S_{i}^{m}, A_{j}^{f}, S_{j}^{f}\right)}{\partial A_{i}^{m} \partial A_{j}^{f}}=\alpha \beta Z_{i j}>0
$$

\section{Empirical Procedure}

To find the optimal pairing of men and women as defined by equation (6), the method of maximum likelihood is utilized to estimate the household production function. To do so, index values of each type of male and female are first determined by using initial guess values for the parameters. The range of $M_{i}$ and $F_{j}$ is then partitioned into five equal segments, for computational ease, to universally rank individuals in the marriage market such that, high type males (females) occupy the higher range of $M_{i}\left(F_{j}\right)$, while the low-type males (females) are found in the lower range of $M_{i}\left(F_{j}\right)$. That is, $M_{1}<M_{2}<M_{3}<M_{4}<M_{5}$ and $F_{1}<F_{2}<F_{3}<F_{4}<F_{5}$.

To illustrate the essence of efficiency in marriage markets, the match utility is defined explicitly over two types of production goods:

$U=U(Z ; Y)$

where $Z$ is the household production technology and $Y$, represents the non-pecuniary production good, which is the indicator of marriage type, with $Y=0,1$. Marriages of $Y=1$ represent efficient matches i.e. matches along the main diagonal that maximize match utility, and marriages of $Y=0$ represent nonefficient matches. To derive the optimal marriage pairings of males and females the method of maximum likelihood is then used to estimate the following model:

$$
\begin{aligned}
& Y=1 \text { if } Z_{i i} \geq Z_{i j} \Rightarrow \varepsilon_{i j} \leq M_{i} F_{i}-M_{i} F_{j}=F(W) \\
& Y=0 \text { if } Z_{i i}<Z_{i j} \Rightarrow \varepsilon_{i j}>M_{i} F_{i}-M_{i} F_{j}=1-F(W)
\end{aligned}
$$

where $W=M_{i} F_{i}-M_{i} F_{j}$.

The model is made operational by a particular choice of distribution for the disturbance. The disturbances are assumed to be independently and identically exponentially distributed. The log likelihood function is then given by:

$$
\ln L=\sum_{Y=0} \ln \left[e^{-\lambda W}\right]+\sum_{Y=1} \ln \left[1-e^{-\lambda W}\right]
$$

where $\gamma^{2}=\frac{1}{\lambda^{2}}$, variance of the exponential distribution, measures the dispersion in match production from the main diagonal. 


\section{Description Of The Data}

To estimate the empirical model of spouse selection developed in this paper, data from a survey of households in India for a study titled "Poverty, Gender Inequality and Reproductive Choice" is used. The fieldwork for this study was carried out by the National Council of Applied Economic Research (NCAER), New Delhi, between July 1995 and September 1995. A total of 1078 households spread over 5 districts in Uttar Pradesh (north India) and 800 households in 5 districts of Karnataka (south India) were surveyed on a range of issues covering social, economic and demographic features of households, as well as exercise of reproductive choice as seen through patterns of contraceptive use by couples in reproductive age groups. Districts were chosen to represent the agroclimatic diversities of each state. The study covered 35 villages in each state averaging 7-9 villages per district. After eliminating the households with missing data 1037 observations were left spread more or less evenly across the five districts of Uttar Pradesh and Karnataka.

The term dowry has been employed in a number of ways in the literature. It is defined here to mean the net exchange of all cash and in-kind gifts made from the bride household to the groom household at the time of marriage and the expenses incurred in marriage ceremonies by the bride household net of those incurred by the groom household. Additionally monetary transfers were made at vastly different points in time, with the earliest marriage dating to 1956 and the most recent to 1994 . To deal with this problem, all net dowry values were converted to constant 1994 prices.

Descriptive statistics of the variables employed in the analysis are presented in Table 1. Numbers in the bottom row and last column refer to the means and standard deviations of the bride and groom characteristics respectively. For instance, the grooms on average were older (by six years) and more educated (by approximately three years) than their brides and received a dowry of Rs. 1, 44,492.7 on average at the time of marriage. The correlation coefficients between bride and groom traits are listed as the main elements of the cross table. Becker characterizes all the traits considered in the empirical analysis as complements; positive correlations are observed on all of them. The correlations suggest that individuals like to pair with those who are similar to them with respect to all nonmarket traits, although this preference is stronger for age than schooling.

\section{Results}

Parameter estimates of the household production function are reported in Table 2, column 1. Results support Becker's prediction of positive assortative mating on nonmarket traits as coefficients of all observed spouse traits are positive. That is, results suggest that spouse age and schooling are complements in the household production function. Of the observable characteristics, while the years of schooling of the groom has the largest effect on matching behavior, it is the age of the bride that affects mate selection and the organization of marriage markets in India.

Such trade-offs between characteristics are expected, because husbands and wives have traditionally had different roles and each has emphasized different qualities in a marriage partner. Marriage has often been seen as the exchange of a man's income earning potential, proxied in the matching process by his years of schooling, for a woman's ability to bear children and manage a household, indicated by her age, which are rough proxies for her beauty and health (Bergstrom and Bagnoli 1993). It follows that the outcome of the process of mate selection is almost entirely driven by the economic assets of the male, his schooling, and the noneconomic assets of the female, her age.

Table 3, Panel A, presents the estimated match matrix. The matches reveal the expected, though not strong, diagonal pattern indicating that thirty-four percent of the marriages in India occur between similar types of males and females. On an absolute basis, however, the phenomenon of assortative mating is strongest at the extremes, suggesting a larger magnitude of marriages between young and illiterate males and females on one hand and older and more educated males and females on the other. 
To examine the role of dowries in match formation in India, the estimates presented in Table 2, column 2 include dowry along with age and years of schooling of a female in the construction of her marriageability index (see equation 5). The results suggest that positive assortative mating on all measured dimensions is the norm. Moreover, the results again imply that marriage markets in India operate to a large extent through the exchange of female's age, characteristics signaling her beauty and health and thus reproductive potential, for male's economic traits, which are based largely on his years of schooling and thus income earning potential.

Table 3, Panel B presents the match matrix with dowry. The equilibrium sorting shows an increase in the number of matches along the diagonal from thirty-four percent in Panel A to thirty-eight percent in Panel B. This variation in the degree of assortative mating is expected, because as more characteristics of those marrying are considered, the shocks to match production should decrease and hence the matches in the marriage market should become more and more symmetrical. This is also reflected in the degree of dispersion in the match production; a greater dispersion means more match heterogeneity. Results in Table 2 reveal that the shocks to match production decrease as dowry is introduced in the model. Thus, dowry increases the likelihood of women marrying men of similar type, thereby improving the efficiency of marriage markets in India.

This is an important result as it lends support to the argument that dowries compensate for bride-groom quality differences. Prior research (Dalmia 2003) suggests that marriage transactions "equalize" the value of marriage services exchanged by the households of the bride and groom. A possible explanation for the improved efficiency of marriage markets in India with the introduction of dowry is that couples with equivalent index values need not be similar with respect to all characteristics relevant to spouse selection. Their overall similarity may result from a balance of pluses and minuses in different traits. Therefore, when a woman marries a man with more education, monetary transfers from her household to the groom and his household may increase her attractiveness in the marriage market and hence accentuate her marriageability index. Thus, the prospect of such resources is likely to increase matches between men and women of similar type, when considered on multivariate dimensions, and improve the efficiency of marriage markets in India.

\section{Conclusion}

This paper examines how equilibrium sorting takes place in marriage markets in India. It constructs an empirical model of spouse selection based on Becker's (1973) efficient marriage market hypothesis, in which optimal assignments of marriage partners are derived from maximizing the household output function. By specifying a marital production function and introducing the influence of multiple individual characteristics simultaneously in the matching technology, this paper creates a matching algorithm and uses the estimated parameters to examine positive assortative mating with respect to nonmarket characteristics. To capture heterogeneity in personal characteristics and to measure how good a partner each individual will make, it constructs a marriage index for all males and females in the marriage market. It utilizes parametric techniques to universally rank men and women by their marital endowment and forms match matrices based on this information.

The maximum likelihood estimates of the structural model support Becker's predictions of positive assortative mating with respect to age and years of schooling suggesting that these traits are complements in the household production function. Results also reveal that while the outcome of the process of mate selection is driven by the schooling of the groom, it is the age of the bride that has the largest affect on matching behavior in India. Most importantly, results show that dowry increases the likelihood of women marrying men of similar type and hence increases the efficiency of marriage markets in India. This is an important result, as it lends support to the equalizing differences role of marital arrangements in India (Dalmia 2003). Moreover, it has important policy implications for the institution of dowry in India. 
Table 1: Descriptive Statistics

\begin{tabular}{|l|c|c|c|c|}
\hline & \multicolumn{3}{|c|}{ Bride } \\
\hline Groom & Age & Years of Schooling & $\begin{array}{c}\text { Net Dowry } \\
\text { (1994 rupees) }\end{array}$ & $\begin{array}{c}\text { Mean } \\
\text { (grooms) }\end{array}$ \\
\hline Age & $0.723^{*}$ & $0.191^{*}$ & $-0.088^{*}$ & 22.21 \\
& & & & $(5.36)$ \\
\hline Years of Schooling & $0.112^{*}$ & $0.498^{*}$ & $0.101^{*}$ & 4.75 \\
& & & 1 & $14.76)$ \\
\hline Net Dowry & $-0.128^{*}$ & 0.04 & & $(164492.7$ \\
\hline $\begin{array}{l}\text { Mean } \\
\text { (brides) }\end{array}$ & 16.22 & 2.06 & $14472.1)$ \\
\hline
\end{tabular}

*Standard deviations in parenthesis

Table 2: Maximum Likelihood Estimates Of The Household Production Function

\begin{tabular}{|l|c|c|}
\hline \multirow{2}{*}{ Parameters } & \multicolumn{2}{|c|}{ Estimates } \\
\cline { 2 - 3 } & Col. 1 & Col. 2 \\
\hline Groom's Age & 0.336 & 0.467 \\
& $(0.025)$ & $(0.026)$ \\
\hline Groom's Schooling & 0.664 & 0.533 \\
& $(0.025)$ & $(0.026)$ \\
\hline Bride's Age & 0.724 & 0.602 \\
& $(0.019)$ & $(0.010)$ \\
\hline Bride's Schooling & 0.276 & 0.120 \\
& $(0.019)$ & $(0.010)$ \\
\hline Dowry & & 0.278 \\
& & $(0.011)$ \\
\hline Variance & 68.30 & 20.23 \\
\hline Log Likelihood & -821.8 & -781.3 \\
\hline
\end{tabular}

*Standard deviations in parenthesis

Table 3: Match Matrices

\begin{tabular}{|c|c|c|c|c|c|c|}
\hline \multicolumn{7}{|c|}{ Panel A: Without Dowry (34\% on Diagonal) } \\
\hline & $\mathbf{F}_{1}$ & $\mathbf{F}_{2}$ & $\mathbf{F}_{3}$ & $\mathbf{F}_{4}$ & $\mathbf{F}_{5}$ & Total \\
\hline $\mathrm{M}_{1}$ & 97 & 52 & 45 & 11 & 2 & 207 \\
\hline $\mathrm{M}_{2}$ & 38 & 56 & 42 & 52 & 19 & 207 \\
\hline $\mathrm{M}_{3}$ & 38 & 32 & 51 & 46 & 40 & 207 \\
\hline $\mathrm{M}_{4}$ & 24 & 47 & 45 & 47 & 44 & 207 \\
\hline $\mathrm{M}_{5}$ & 10 & 20 & 24 & 51 & 102 & 207 \\
\hline Total & 207 & 207 & 207 & 207 & 207 & 1035 \\
\hline \multicolumn{7}{|c|}{ Panel B: With Dowry (38\% on Diagonal) } \\
\hline & $\mathbf{F}_{1}$ & $\overline{F_{2}}$ & $\overline{F_{3}}$ & $\mathbf{F}_{4}$ & $\mathbf{F}_{5}$ & Total \\
\hline $\mathrm{M}_{1}$ & 117 & 37 & 38 & 10 & 5 & 207 \\
\hline $\mathrm{M}_{2}$ & 45 & 56 & 48 & 39 & 19 & 207 \\
\hline $\mathrm{M}_{3}$ & 26 & 61 & 54 & 44 & 22 & 207 \\
\hline $\mathrm{M}_{4}$ & 16 & 37 & 34 & 62 & 58 & 207 \\
\hline $\mathrm{M}_{5}$ & 3 & 16 & 33 & 52 & 103 & 207 \\
\hline Total & 207 & 207 & 207 & 207 & 207 & 1035 \\
\hline
\end{tabular}




\section{References}

1. Becker, Gary S. 1973. “A Theory of Marriage: Part I”, Journal of Political Economy, 81, 813-46.

2. $\quad---1$ 1991. A Treatise on the Family, enlarged edition, Cambridge, MA: Harvard University Press.

3. Bergstrom, T., and M. Bagnoli. 1993. "Courtship as a Waiting Game", Journal of Political Economy, 101, 185-202.

4. Bergstrom, Theodore. 1997. "A Survey of Theories of the Family", in Rosenzweig, Mark R. and Oded Stark, eds., Handbook of Population and Family Economics, Amsterdam: Elsevier, 21-79.

5. Bhat, P. N. M, and S. A. Halli. 1999. "Demography of Bride Price and Dowry: Causes and Consequences of the Indian Marriage Squeeze", Population Studies, 53, 129-148.

6. Dalmia Sonia. 2003. "A Hedonic Analysis of Marriage Transactions in India: Estimating Demand for Dowries and Groom Characteristics in Marriage", working paper, Grand Valley State University.

7. Edlund, Lena. 1999. "Son Preference, Sex Ratios, and Marriage Patterns", Journal of Political Economy, 107, 1257-1304.

8. Epstein, E., and Ruth Guttman. 1984. "Mate Selection in Man: Evidence, Theory, and Outcome", Social Biology, 31, 243-278.

9. Gale, D., and L. Shapley. 1962. "College Admissions and the Stability of Marriage", American Mathematical Monthly, 69, 9-15.

10. Goody, J. 1973. "Bridewealth and Dowry in African and Eurasia", in J. Goody and S.J.Tambiah, Ed. Bridewealth and Dowry, New York: Cambridge University Press.

11. Jepsen, L. K., and Christopher A. Jepsen. 2002. "An Empirical Analysis of the Matching Patterns of SameSex and Opposite-Sex Couples”, Demography, 39, 435-453.

12. Lam, David. 1988. "Marriage Markets and Assortative Mating with Household Public Goods", Journal of Human Resources, 23, 462-487.

13. Mare, Robert D. 1991. "Five Decades of Educational Assortative Mating", American Sociological Review, 56, 15-32.

14. Mortensen, Dale T. 1988. "Matching: Finding a Partner for Life or Otherwise", American Journal of Sociology, 94, S215-S240.

15. Nakosteen, R. A., and Michael A. Zimmer. 2001. "Spouse Selection and Earnings: Evidence of Marital Sorting", Economic Inquiry, 39, 201-213.

16. Rao, V. 1993. "The Rising Price of Husbands: A Hedonic Analysis of Dowry Increases in Rural India", Journal of Political Economy 101, 666-677.

17. Suen, W., and Hon-Kwong Lui. 1999. "A Direct Test of the Efficient Marriage Market Hypothesis", Economic Inquiry, 37, 29-46.

18. Weiss, Yoram. 1977. "The Formation and Dissolution of Families: Why Marry? Who Marries Whom? and What Happens Upon Divorce", in Rosenzweig, Mark R. and Oded Stark, eds., Handbook of Population and Family Economics, Amsterdam: Elsevier, 81-123.

19. Zhang, J., and Pak-Wai Lui. 2003. "Testing Becker's Prediction on Assortative Mating on Spouse's Wages”, The Journal of Human Resources, 38, 99-110. 